University of New Orleans

ScholarWorks@UNO

$1-13-2012$

\title{
One-pot Synthesis in Polyamines for Preparation of Water-soluble Magnetite Nanoparticles with Amine Surface Reactivity
}

\author{
Haiou Qu \\ University of New Orleans \\ Hui Ma \\ University of New Orleans \\ Aurélien Riviere \\ University of Bordeaux \\ Weilie Zhou \\ University of New Orleans, wzhou@uno.edu \\ Charles J. O'Connor \\ University of New Orleans, coconnor@uno.edu
}

Follow this and additional works at: https://scholarworks.uno.edu/chem_facpubs

Part of the Materials Chemistry Commons, and the Materials Science and Engineering Commons

\section{Recommended Citation}

H. Qu, H. Ma, A. Riviere, W. Zhou, and C.J. O'Connor, "One-pot synthesis in polyamines for preparation of water-soluble magnetite nanoparticles with amine surface reactivity," J. Mater. Chem., 2012, 22(8): 3311-3313.

This Article is brought to you for free and open access by the Department of Chemistry at ScholarWorks@UNO. It has been accepted for inclusion in Chemistry Faculty Publications by an authorized administrator of ScholarWorks@UNO.For more information, please contact scholarworks@uno.edu. 


\title{
Journal of

\section{One-pot synthesis in polyamines for preparation of water-soluble magnetite nanoparticles with amine surface reactivity $\dagger$}

\author{
Haiou Qu, ${ }^{a b}$ Hui Ma, ${ }^{a b}$ Aurélien Riviere, ${ }^{c}$ Weilie Zhou ${ }^{b}$ and Charles J. O'Connor ${ }^{* a b}$ \\ Received 16th November 2011, Accepted 5th January 2012 \\ DOI: 10.1039/c2jm15932e
}

\begin{abstract}
Magnetite nanoparticles with hydrophilic surface coating are prepared in polyamine solvents. The resulting products are highly stable in polar solvent. The surface amine groups are available for secondary reactions.
\end{abstract}

Superparamagnetic iron oxide nanoparticles (SPIONs) have received attention mostly due to their potential to stimulate applications in clinical areas. Numerous studies have been reported on using SPIONs for target delivery, magnetic resonance imaging (MRI), hyperthermia and magnetic separation. ${ }^{1}$ The majority of these studies adopted thermal decomposition of several iron precursors in nonpolar solvent as the method to prepare SPIONs because of the high degree of uniformity, crystallinity and magnetic properties that can be achieved by this route. ${ }^{2}$ However, the resulting nanoparticles (NPs) are hydrophobic on the surface and capped by monofunctional ligands which are unable to sustain a secondary reaction for further modification. Consequently, these NPs are usually treated with sophisticated room temperature ligand exchange reaction to modify the surface moiety with desired functionalities. ${ }^{3}$ Although co-precipitation and microemulsion methods can offer NPs with good solubility in aqueous solution, ${ }^{4}$ a relatively lower degree of control over the size distribution and crystallinity still limit their practical applications.

Several high-temperature synthetic approaches have been developed to prepare water-soluble SPIONs by performing the synthesis in polar solvent at elevated temperature. ${ }^{5}$ Not only can these high boiling point polar solvents (i.e. diethylene glycol and 2-pyrrolidone) provide a wide operating-temperature range, they also act as reducing agents and coordinating ligands that can effectively stabilize the NPs during the reaction and prevent aggregation. ${ }^{6}$ Despite interest in direct preparation of uniform water-soluble NPs, the reactivity and availability of the surface functional groups of ligand shell remain an

${ }^{a}$ Department of Chemistry, University of New Orleans, 2000 Lakeshore Dr, New Orleans, LA, USA

${ }^{b}$ Advanced Materials Research Institute, University of New Orleans, 2000 Lakeshore Dr, New Orleans, LA, USA. E-mail: coconnor@uno.edu.; Fax: +504-280-3185; Tel: +504-280-6848

${ }^{c}$ Chemistry Department, University of Bordeaux, Cours de la Liberation, Talence, France

$\uparrow$ Electronic Supplementary Information (ESI) available: Experimental procedure, XRD, XPS, FT-IR, and results from photoluminescence measurement and magnetic properties measurement. See DOI: $10.1039 / \mathrm{c} 2 \mathrm{jm} 15932 \mathrm{e}$ issue, which hinders the subsequent functionalization step for designing complicate multifunctional agent for clinical diagnostic and treatment.

Besides carboxylates, ${ }^{7}$ phosphates,${ }^{8}$ and sulfates,${ }^{2 a}$ primary amines are also known to bind to the surface of NPs due to their coordinating ability with many transition metals. ${ }^{2 c, 9}$ While ligand exchange reactions and hydrothermal synthesis of iron oxide NPs using hydrophilic molecules containing amine functionalities as ligand have been reported, ${ }^{2 a, 10}$ the colloidal chemistry using polyamines as solvent and stabilizing agents is unexplored, and little attention has been paid to their interesting properties such as high boiling point, watersolubility and reduction abilities. Additionally, amine groups are also well-known for their reactivity in bioconjugation chemistry. A variety of organic molecules are able to couple with amine-containing molecules and give a stable amide or secondary amine bond in a rapid and high yield reaction. ${ }^{11}$ Herein, we report a one-pot synthesis method, using polyamine as both solvent and stabilizing agents to prepare water-soluble amine functionalized $\mathrm{Fe}_{3} \mathrm{O}_{4} \mathrm{NPs}$.

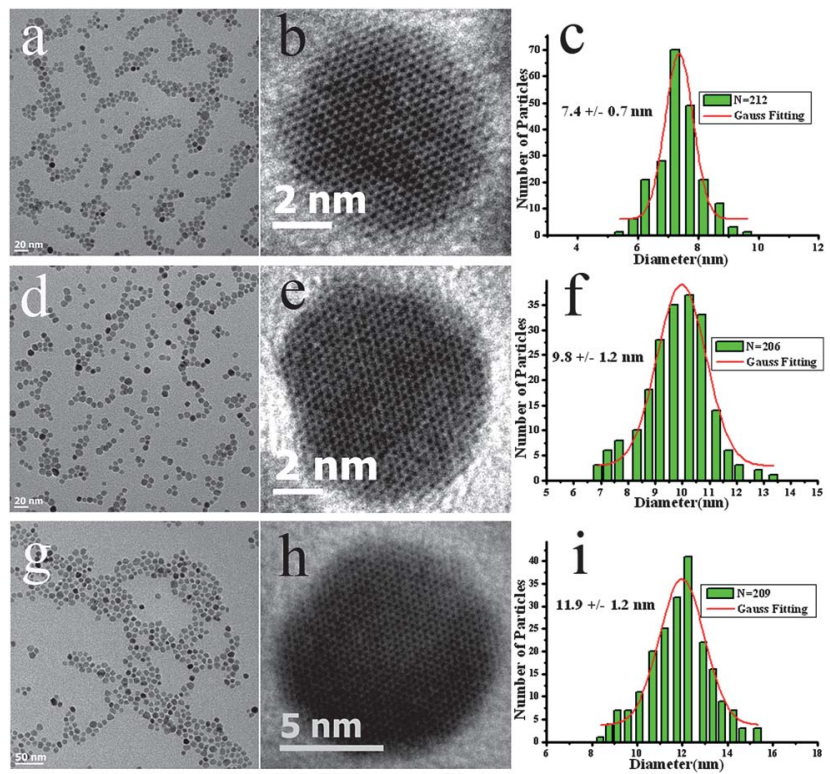

Fig. 1 TEM images and size statistics for $\mathrm{Fe}_{3} \mathrm{O}_{4}$ NPs: (a,d,g) low resolution, (b,e,h) high resolution, (c,f,i) size distribution of different sized $\mathrm{Fe}_{3} \mathrm{O}_{4}$ NPs. 
Fig. 1a is a typical transmission electron microscopy (TEM) image of as-prepared $\mathrm{Fe}_{3} \mathrm{O}_{4}$ NPs. The narrowly distributed NPs with an average size of $7.4 \mathrm{~nm}(\mathrm{SD}=9.5 \%)$ can be easily achieved by refluxing iron source in polyamine without any size selection process (see ESI $\dagger$ ). Synthesis conditions such as concentration of the precursors, heating rate were varied to understand the formation of the NPs. It is suggested that mild heating ramp is important to achieve narrow size distribution while rapidly heating the system from room temperature to reflux $\left(20^{\circ} \mathrm{C} \mathrm{min}{ }^{-1}\right)$ would result in NPs with broad size distribution (Fig. S1 $\dagger$ ). Uniform $\mathrm{Fe}_{3} \mathrm{O}_{4}$ NPs with larger diameter can be accomplished via a seed-mediated growth method. By mixing the seeds, $7.4 \mathrm{~nm}$ NPs, with more iron precursors, the average diameter is increased to $9.8 \mathrm{~nm}(\mathrm{SD}=12.2 \%)$. Following the same procedure, $12 \mathrm{~nm}$ or larger NPs can be prepared. The histogram of each size group of the $\mathrm{Fe}_{3} \mathrm{O}_{4} \mathrm{NPs}$ is given in Fig. 1 and examination of this figure shows that different sized $\mathrm{Fe}_{3} \mathrm{O}_{4} \mathrm{NPs}$ are all quasi-spherical with small size deviations.

High resolution TEM (Fig. 1) and XRD studies (Fig. S2†) confirm good crystallinity and phase purity of the as prepared NPs, and the XRD pattern matches well with the standard bulk magnetite (JCPDS no 19-0629). Previous studies have shown that, metal precursors can be reduced and yield nucleation in the present of primary amines. ${ }^{9,12}$ Similar results are observed in the present study, indicating a vital role of hydrophilic TETA in the synthesis of iron oxide NPs. Although, a clear mechanism is not yet fully understood, polyamines are believed to provide a reductive environment to partially reduce the iron precursors and facilitate the nucleation and subsequent growth period.

The magnetic properties were studied in a Quantum Design SQUID magnetometer (MPMS XL-7) and $\mathrm{Fe}_{3} \mathrm{O}_{4}$ NPs of all sizes exhibit superparamagnetism at $300 \mathrm{~K}$ (Fig. S3†). The weight percentages of $\mathrm{Fe}_{3} \mathrm{O}_{4}$ NPs in different sizes were acquired by TGA and confirmed by ICP-AES. After normalizing to the magnetic core, the saturation magnetizations of pure $\mathrm{Fe}_{3} \mathrm{O}_{4}$ are $75.8 \mathrm{emu} \mathrm{g}{ }^{-1}$, $79.5 \mathrm{emu} \mathrm{g}^{-1}$ and $82.0 \mathrm{emu} \mathrm{g}^{-1}$ respectively, which are very close to the value of magnetite NPs in similar size reported in the literature. .c, 12,13 $^{2,13}$

The surface composition of as-synthesized NPs was studied by FT-IR and XPS. As shown in Fig. S4, as-prepared NPs give similar spectrum as neat TETA. The peak at $1600 \mathrm{~cm}^{-1}$ is assigned to $\mathrm{N}-\mathrm{H}$ bending, and the peaks in $2800 \mathrm{~cm}^{-1}$ to $3000 \mathrm{~cm}^{-1}$ region are corresponded to the symmetric and asymmetric $\mathrm{CH}_{2}$ stretches, which indicate that as-prepared $\mathrm{Fe}_{3} \mathrm{O}_{4} \mathrm{NPs}$ are coated with polyamine molecules (see ESI $\dagger$ for detailed calculation). As reported in the literature, the binding energy of $\mathrm{N} 1 \mathrm{~s}$ will shift to lower value if a chemical bond is formed between the nitrogen and metal elements. ${ }^{5 b}$ From XPS study (Fig. S5†), we observed that the binding energy of $\mathrm{N}$ 1s was sifted to $369.9 \mathrm{eV}$, indicating a direct coordination of nitrogen with iron, which directly prove the presence of TETA as capping ligand on the surface of NPs. The TETA protected NPs can be easily dispersed in polar solvents such as alcohols, DMSO and water or buffer solutions for several months without any precipitates. The small polydispersity from DLS measurement (Table S1 $\dagger$ ) also confirm the good colloidal stability of polyamine coated NPs. Additionally, ascribed to the protonation of multiple amine groups from polyamine molecules, TETA coated NPs are highly positively charged in aqueous solution.

The surface moiety of NPs should not only tolerate different reaction conditions to protect the inner core materials, but also present enough reactivity and availability for secondary modification. As indicated from IR and zeta potential measurement, there are free amine groups dangling near the surface of the TETA coated NPs, which provide possible reaction sites for further modification. We have adopted two pathways to study the surface reactivity. Previous studies have shown that amine-functionalized NPs can be used for noble metal NPs or quantum dots (QDs) attachment. ${ }^{14}$ Herein, negatively charged gold crystals with an average diameter of $3 \mathrm{~nm}$ were used. From TEM study (Fig. 2a), small gold nanocrystals are uniformly attached onto the surface of $\mathrm{Fe}_{3} \mathrm{O}_{4}$ NPs. No observable change was found in TEM study after a one hour sonication treatment, implying a strong affinity of gold to amine groups. Similarly, QDs can also be decorated to the surface of NPs via their affinity with amines (see ESI $\dagger$ ).

Besides their affinity with transition metal elements, amine groups are also expected to be reactive in organic reactions. For example, under the activation of zero length linker EDC, biocompatible polymer polyacrylic acid (PAA) was coupled to the surface of magnetite NPs via amine side. The significant changes in the zeta potential values and weight percentage in organic layer from ICP measurement suggest a successful coupling. Additionally, from FT-IR study (Fig. 2b), the two intense peaks at $1581 \mathrm{~cm}^{-1}$ and $1414 \mathrm{~cm}^{-1}$ are assigned to asymmetric and symmetric COOstretching. The absorption peak corresponding to $\mathrm{C}=\mathrm{O}$ of carboxylic group is located at $1704 \mathrm{~cm}^{-1}$, which also demonstrates that the conjugation between free amine group and PAA is achieved. TEM studies showed that this functionalization does not cause any effect on the shape or size of the NPs. Biocompatible polymer coating can prolong the circulation time and effectively reduce nonspecific interaction with protein and other biomolecules, which makes the surface modified iron oxide NPs promising candidate as contrast agent in MRI.

Many studies have shown that magnetic NPs can be applied in separation of bio-related molecules. Here, the strong binding between biotin and streptavidin was chosen as a model to test the potential of polyamine coated magnetite NPs in bioseparation. Biotin was first conjugated to the as-prepared NPs under similar reaction condition as in PAA conjugation. FT-IR scan shows that a strong amide bond located at $1681 \mathrm{~cm}^{-1}$ (Fig. S6 $\dagger$ ) appeared after the conjugation. From TEM study, no obvious difference was observed after the coupling of biotin. To test their ability in bioseparation, the biotin conjugated NPs dispersion was added to a PBS buffer containing FITC-labeled

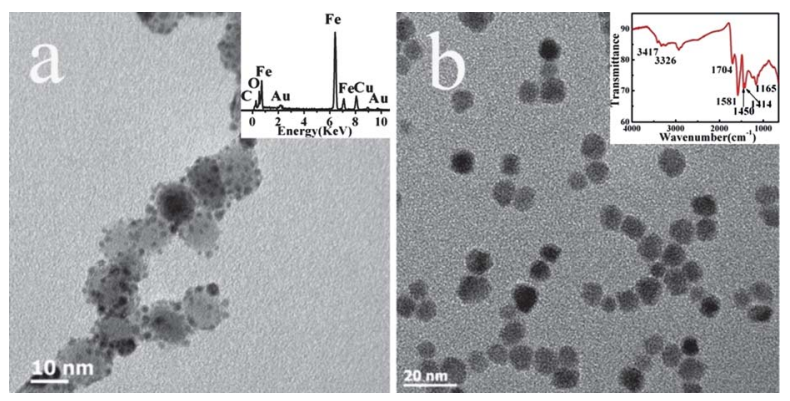

Fig. 2 (a) TEM image of gold nanocrystals attached $\mathrm{Fe}_{3} \mathrm{O}_{4} \mathrm{NPs}$ (inset: EDS scan of $\mathrm{Au} @ \mathrm{Fe}_{3} \mathrm{O}_{4}$ ). (b) TEM image of $\mathrm{Fe}_{3} \mathrm{O}_{4} \mathrm{NPs}$ functionalized with PAA (inset: FT-IR spectrum of $\mathrm{Fe}_{3} \mathrm{O}_{4} \mathrm{NPs}$ after functionalization with PAA). 
streptavidin. After shaking for $30 \mathrm{~min}$, the solid product was collected with a small permanent magnet and the solution was measured. As illustrated in the emission spectra (Fig. S7 $\uparrow$ ), the fluorescent intensity dropped to only $4 \%$ of the initial intensity. As a control group, as-prepared $\mathrm{Fe}_{3} \mathrm{O}_{4} \mathrm{NPs}$ without biotin conjugation were also incubated with FITC-labeled streptavidin for $30 \mathrm{~min}$ and collected with a magnet. The fluorescent intensity of the remaining solution still exhibited $80 \%$ intensity of the origin (Fig. S8 $\dagger$ ), indicating that the sharp intensity drop must result from the effective binding of biotin$\mathrm{Fe}_{3} \mathrm{O}_{4}$ NPs with streptavidin rather than non-specific interaction with the proteins. The biotinylated $\mathrm{Fe}_{3} \mathrm{O}_{4}$ NPs were also mixed with $\mathrm{Cy} 5$ labeled normal mouse $\mathrm{IgG}$, and $90 \%$ of the intensity remained after the separation (Fig. S9†), implying a very limited non-specific interaction with irrelevant proteins. The fluorescent images of isolated NP dispersion under UV light (Fig. 3a) gave a direct-viewing of the efficient separation process. We also tested their separation ability in a mixture of different types of proteins. Under identical experimental condition, a mixture of $\mathrm{Cy} 5$ labeled normal mouse $\mathrm{IgG}$ and FITClabeled streptavidin was incubated with biotin- $\mathrm{Fe}_{3} \mathrm{O}_{4} \mathrm{NPs}$. The separation process (Fig. 3b) caused only 13\% decrease of fluorescent intensity in Cy5 while $91 \%$ of the FITC-labeled streptavidin was collected during the process. Meanwhile, the fluorescent color of the solution was changed from yellow to red during the separation, which implies that streptavidin are specifically separated by biotin$\mathrm{Fe}_{3} \mathrm{O}_{4}$ NPs.

We describe a wet chemistry synthesis procedure to prepare narrowly distributed, spherical shaped magnetite NPs with controlled size using polyamines as solvent, reducing and stabilizing agents. The surface moiety not only stabilizes NPs in various polar solvent, they also provide functional groups that are available for either attachment of a different nanomaterial or biomolecules conjugations. Separation of streptavidin from a mixture of protein using biotin linked NP clearly demonstrated the potential of the magnetite NPs

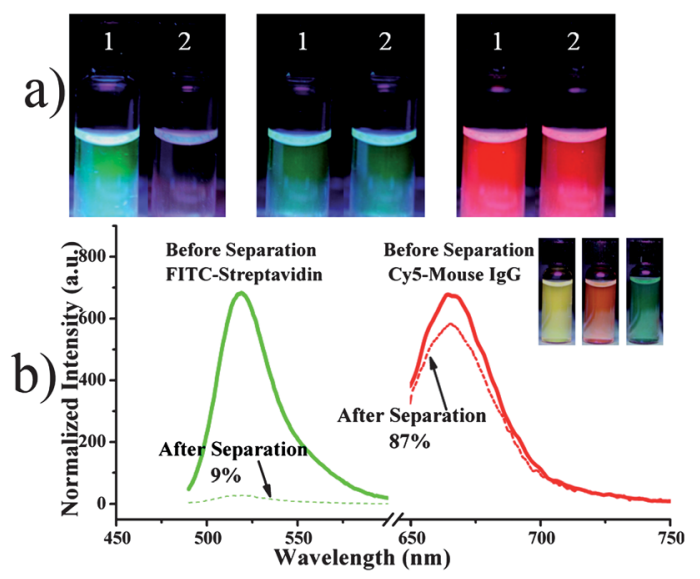

Fig. 3 (a) Fluorescent images from the solutions 1: before and 2: after mixing with the nanoparticles. Left and middle: biotinylated and asprepared $\mathrm{Fe}_{3} \mathrm{O}_{4}$ NPs with FITC-streptavidin. Right: biotinylated $\mathrm{Fe}_{3} \mathrm{O}_{4}$ NPs with Cy5-IgG, (b) fluorescence spectra from the mixture solutions of FITC-streptavidin and normal mouse IgG labeled by $\mathrm{Cy} 5$ before and after treating with biotinylated $\mathrm{Fe}_{3} \mathrm{O}_{4} \mathrm{NPs}$ (inset: fluorescent images showing the separation process. Left: before, middle: after treating with biotinylated $\mathrm{Fe}_{3} \mathrm{O}_{4}$, right: redispersed $\mathrm{Fe}_{3} \mathrm{O}_{4}$ NPs separated FITC-streptavidin). prepared by our method in bioseparation applications. A systematic study is under way to understand the synthesis mechanism. We expect these findings will help us extend this method to the synthesis of other transitional metal ferrite nanoparticles.

This work was supported by a research grant from Louisiana Board of Regents contract no. LEQSF (2007-12)-ENH-PKSFIPRS-04. We thank Dr Baobao Cao for his help in the TEM study and Kai Wang for helpful discussions.

\section{Notes and references}

1 (a) F. Dilnawaz, A. Singh, C. Mohanty and S. K. Sahoo, Biomaterials, 2010, 31, 3694; (b) N. Nitin, L. E. W. LaConte, O. Zurkiya, X. Hu and G. Bao, JBIC, J. Biol. Inorg. Chem., 2004, 9, 706; (c) K. Hayashi, M. Moriya, W. Sakamoto and T. Yogo, Chem. Mater., 2009, 21, 1318; (d) C. Xu, K. Xu, H. Gu, R. Zheng, H. Liu, X. Zhang, Z. Guo and B. Xu, J. Am. Chem. Soc., 2004, 126, 9938.

2 (a) S. Laurent, D. Forge, M. Port, A. Roch, C. Robic, L. Vander Elst and R. N. Muller, Chem. Rev., 2008, 108, 2064; (b) J. Park, K. An, Y. Hwang, J.-G. Park, H.-J. Noh, J.-Y. Kim, J.-H. Park, N.-M. Hwang and T. Hyeon, Nat. Mater., 2004, 3, 891; (c) S. Sun and H. Zeng, J. Am. Chem. Soc., 2002, 124, 8204; (d) K. Woo, J. Hong, S. Choi, H.-W. Lee, J.-P. Ahn, C. S. Kim and S. W. Lee, Chem. Mater., 2004, 16, 2814; (e) P. Guardia, N. Pérrez, A. Labarta and X. Batlle, Langmuir, 2009, 26, 5843.

3 (a) H. Gu, Z. Yang, J. Gao, C. K. Chang and B. Xu, J. Am. Chem. Soc., 2004, 127, 34; (b) M. S. Nikolic, M. Krack, V. Aleksandrovic, A. Kornowski, S. Förster and H. Weller, Angew. Chem., Int. Ed., 2006, 45, 6577; (c) M. Lattuada and T. A. Hatton, Langmuir, 2006, 23, 2158; (d) J. A. Dahl, B. L. S. Maddux and J. E. Hutchison, Chem. Rev., 2007, 107, 2228.

4 (a) J.-R. Jeong, S.-C. Shin, S.-J. Lee and J.-D. Kim, J. Magn. Magn. Mater., 2005, 286, 5; (b) L. A. Harris, J. D. Goff, A. Y. Carmichael, J. S. Riffle, J. J. Harburn, T. G. St. Pierre and M. Saunders, Chem. Mater., 2003, 15, 1367.

5 (a) Z. Li, Q. Sun and M. Gao, Angew. Chem., Int. Ed., 2005, 44, 123; (b) Z. Li, H. Chen, H. Bao and M. Gao, Chem. Mater., 2004, 16, 1391; (c) H. Qu, D. Caruntu, H. Liu and C. J. O'Connor, Langmuir, 2011, 27, 2271

6 (a) W. Cai and J. Wan, J. Colloid Interface Sci., 2007, 305, 366; (b) D. Caruntu, G. Caruntu, Y. Chen, C. J. O'Connor, G. Goloverda and V. L. Kolesnichenko, Chem. Mater., 2004, 16, 5527.

7 (a) N. J. Turro, P. H. Lakshminarasimhan, S. Jockusch, S. P. O’Brien, S. G. Grancharov and F. X. Redl, Nano Lett., 2002, 2, 325; (b) T. Bala, B. L. V. Prasad, M. Sastry, M. U. Kahaly and U. V. Waghmare, J. Phys. Chem. A, 2007, 111, 6183.

8 (a) C. Yee, G. Kataby, A. Ulman, T. Prozorov, H. White, A. King, M. Rafailovich, J. Sokolov and A. Gedanken, Langmuir, 1999, 15, 7111; (b) M. I. Tejedor-Tejedor and M. A. Anderson, Langmuir, 1990, 6, 602 .

9 M. J. Polking, H. Zheng, R. Ramesh and A. P. Alivisatos, J. Am. Chem. Soc., 2010, 133, 2044.

10 W. Leyu, B. Jie, W. Lun, Z. Fang and L. Yadong, Chem.-Eur. J., 2006, 12, 6341.

11 G. T. Hermanson, Bioconjugate Techniques., New York: Academic Press, 1996.

12 Z. Xu, C. Shen, Y. Hou, H. Gao and S. Sun, Chem. Mater., 2009, 21, 1778 .

13 D. Caruntu, G. Caruntu and C. J. O'Connor, J. Phys. D: Appl. Phys., 2007, 40, 5801.

14 (a) X. Teng, D. Black, N. J. Watkins, Y. Gao and H. Yang, Nano Lett., 2003, 3, 261; (b) D. Wang, J. He, N. Rosenzweig and Z. Rosenzweig, Nano Lett., 2004, 4, 409; (c) S. I. Stoeva, F. Huo, J.-S. Lee and C. A. Mirkin, J. Am. Chem. Soc., 2005, 127, 15362; (d) J. Kim, J. E. Lee, J. Lee, Y. Jang, S.-W. Kim, K. An, J. H. Yu and T. Hyeon, Angew. Chem., Int. Ed., 2006, 45, 4789; (e) L. Zhang, W.-F. Dong, Z.-Y. Tang, J.-F. Song, H. Xia and H.-B. Sun, Opt. Lett., 2010, 35, 3297; (f) Y. Gao and Z. Tang, Small, 2011, 7, 2133. 